\title{
Corrosion Behaviour of Passive Layer Growth by Controlling Additives of Nano-Metals-Phosphate to Pure Aluminum
}

\author{
Hussein A. Hussein ${ }^{1, *}$, Mohammed J. Kahdim ${ }^{1}$, Alaa Abdulhasan Atiyah² \\ ${ }^{1}$ Department of Production and Metallurgy Engineering, University of Technology, Baghdad - Iraq \\ ${ }^{2}$ Department of Materials Engineering, University of Technology, Baghdad - Iraq
}

\section{ARTICLE INFO}

Article history:

Received 26 November 2019

Accepted 7 June 2020

Keywords:

Pure Aluminum; Passivity; Pitting corrosion and Nano-metals-phosphate

\begin{abstract}
This study investigates how microstructure and chemistry effects by Nano-MetalPhosphate and the kinetics of growth passive layer and passivity breakdown. Additionally, the passive layer germination behavior on aluminum alloy 1050 with anticorrosive properties. The passive layer is an alloying method which allows an aluminum oxide to germinate. Morphologically and structurally, the aluminum oxide films were characterized using microscopy analyzes and XRD analysis. Results indicated that the reinforcements are well distributed and the grin size is downy. Corrosion behavior tested by Cyclic polarization exam and done at room temperature in (3.5 per cent $\mathrm{NaCl}$ ) solution. The reinforcement increased the hardness for processed aluminum from Hv81.1 to HV=120.492 as castings. The parameter Nano-MetalPhosphate has attenuated the current density of corrosion $(7.15 \mu \mathrm{A} / \mathrm{cm} 2)$ compared to the as-cast sample results.
\end{abstract}

\section{Introduction}

Extensively, aluminum and its alloys are used in many industrial and engineering applications, due to their extreme properties, high mechanical properties, high wear and corrosion resistance, and adequate weight resistance [1]. Metallic materials alloys with their varied compositions are widely used in transport, such as cars, aircraft and parts, as well as in alternative applications such as appliances, technology, construction and containers [2,3]. When these materials are exposed to corrosive media it will corrode and restrict their applications. Although most metallic element alloys develop an oxide layer on their surfaces when exposed to air, their corrosion occurs in a solution containing chloride. [4,5]. Because of the oxide layer, there is not enough ability to stop the attack of high chloride ion concentration on the aluminum surface oxide layer. Here, the aluminum oxide breakdown occurs through localized or pitting corrosion $[6,7]$.

In aggressive environments, there are several trails to assess aluminum's resistance corrosion. These include; the addition of minor percentages of additional passive alloy metals [8]. Alloys showed that coarser dendritic structures higher yield resistance to corrosion than downy dendritic structures, and that this is associated with the interdimeric mixture morphology [9]; Samuel et al. [10] investigated that a further increase in the Fe content, and the size of the-A15Fe platelets, causes an increase in pore sizes, but Platelets also constrict the pores

\footnotetext{
* Corresponding author.

E-mail address: 70082@uotechnology.edu.iq

DOI: $10.24237 /$ djes.2020.13401
} 
growth. Queiroz et al [11]. Aluminum alloys have a very complex microstructure due to heterogeneities resulting in increased localized corrosion; paint the surface with protective coatings [12]; use corrosion inhibitors to decrease the severity of corrosive media; decrease the grain size of the metals used to vary nanoscale $[13,14]$. Changing the grain scale of metals from micro to nanocrystalline microstructure $(<100 \mathrm{~nm})$ to increase the degree volume fraction of grain boundaries is additionally found to improve the physical, chemical and mechanical properties of those materials. Ultrafine-grained materials with nanoscale grain are one of the necessary targets of nanomaterial production in recent decades $[15,16,17]$. Completely different Nano-MetalsPhosphate is process alloy technique that's suitable for spectrum line. In the current study, the addition of Nano-Metal-Phosphate as a modifier of the microstructure and boost of the oxide layer, the mechanical and corrosion properties of pure $\mathrm{Al}$, and their behavior are part of a new technique. X-Ray Diffraction has been evaluated on the crystal size of the manufactured Al, and Vickers hardness has been measured to show the strength of pure-Al.

\section{Experimental procedure}

\subsection{Selection of material}

In this research, investigation the pure aluminum casting was used as a cylindrical mound. For all the experiments, a specimen cylinder size of $\theta 1.5 \mathrm{~cm}$ x L15 cm was used. The aluminum alloy's chemical composition wt percentage. Listed in Table.1. The powderprepared Nano-Metals-Phosphate mixes 0.15 percent of dopant-element size $200 \mathrm{~nm}$ mixed, with pure aluminum powder and compacted in a suitable $10 \mathrm{~mm}$ diameter mold to produce pellets as shown in Table.2. Used in the laboratory to test for changing the size of grain from micro to nano-crystalline microstructure that is used as a modifier material.

Table1. Alloy chemical composition

\begin{tabular}{|c|c|c|c|c|c|c|c|c|c|c|}
\hline Elements & $\mathbf{S i}$ & $\mathbf{F e}$ & $\mathbf{C u}$ & $\mathbf{Z n}$ & $\mathbf{S}$ & $\mathbf{M n}$ & $\mathbf{V}$ & $\mathbf{C r}$ & $\mathbf{T i}$ & $\mathbf{A l}$ \\
\hline \%wt & 0.272 & 0.093 & 0.006 & 0.006 & 0.014 & 0.005 & 0.001 & 0.007 & 0.003 & Bal. \\
\hline
\end{tabular}

Table 2. Pellets composition

\begin{tabular}{|l|c|c|c|}
\hline Material & Wt. added & Al-Pure 99.99\% & Compact pressure /bar \\
\hline $\mathbf{F e}\left(\mathbf{P O}_{4}\right)_{2}$ & o.15 g. & o.3 g. & $150 \mathrm{bar}$ \\
\hline $\mathbf{M g}\left(\mathbf{P O}_{4}\right)$ & o.15 g. & $0.3 \mathrm{~g}$. & $150 \mathrm{bar}$ \\
\hline $\mathbf{Z n}_{3}\left(\mathbf{P O}_{4}\right)$ & o.15 g. & $0.3 \mathrm{~g}$. & $150 \mathrm{bar}$ \\
\hline
\end{tabular}

\subsection{Fabrication of aluminum matrix-dopant elements}

The Samples were made with liquid methods. In the electric resistance furnace, the die material was heated to $750{ }^{\circ} \mathrm{C}$. An inert gas (argon) was used for de-gasification followed by a mechanical stirrer with a rotation speed of $500.0 \mathrm{rpm}$, as shown in Fig.1 At this point, diluents pre-heated at $300^{\circ} \mathrm{C}$ are slowly introduced into the molten slurry to remove any moisture content. A small amount of different types of nano-metalphosphates were added to the molten metal. Slurry stirring was performed for approximately ten minutes to encourage regular wetting and dispersion to enhance. A metered amount of the mixture was poured into a preheated steel mold. The castings were allowed to cool to room temperature in the mold itself, and then were subsequently expelled from the mold. Later all castings were machined to prepare the test sample. 


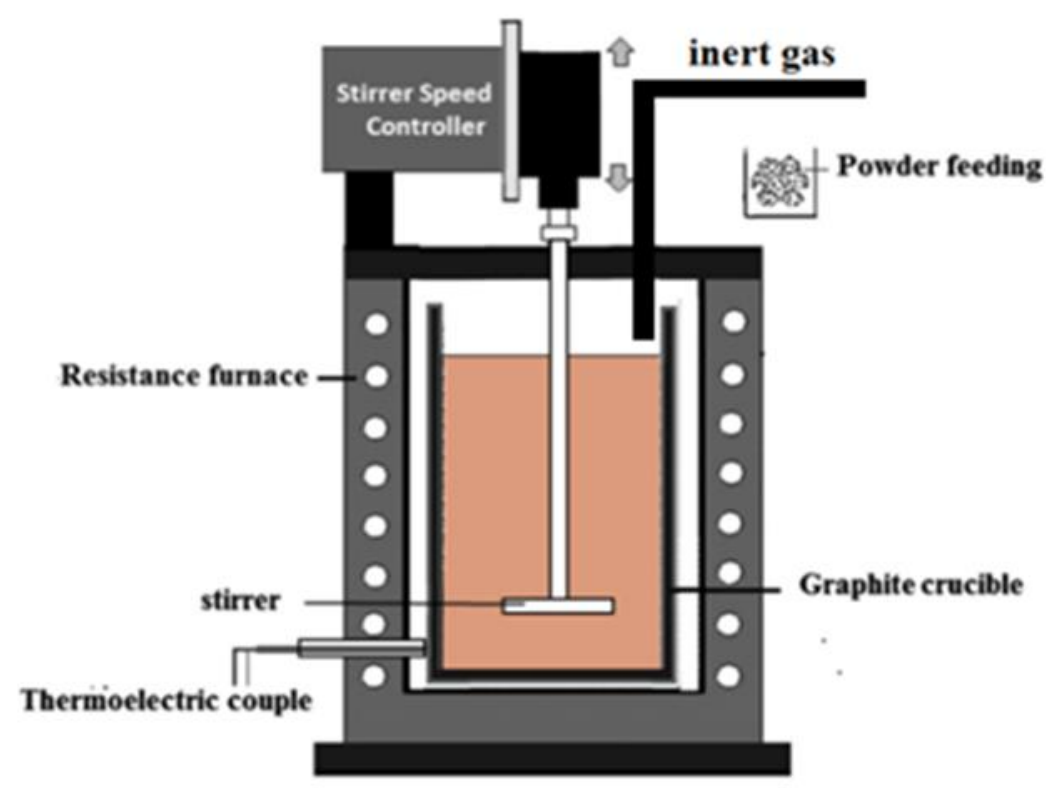

Fig 1. Stir casting process

\subsection{Analysis of microstructural}

Optical microscopes were used to identify different phases and samples of metallic elements to investigate the morphology and potential attacks of completely different local corrosion. The mineral control samples were prepared using milling using 220.0, 3200.0, 600.0, 800.0, 1000.0 and 1200.0 granular sheets, respectively. Finally, the polishing was finished on a piece of cloth with diamond paste, then cleaned and resurfaced in a very correct blunt solution killer, then fixed on an optical microscope and a microscopic structure was observed.

\subsection{Micro hardness test}

Hardness done by a Vickers hardness tester using $0.5 \mathrm{~kg}$, and holding period was $15 \mathrm{~s}$. The measurements were generated at three different locations.

\subsection{X-Ray diffraction analysis}

The phases examined by Shimadzu X-Ray Diffractometer XRD-60.00 X-ray diffractometer available at Nanotechnology Center, U.Technology. X-ray- tube: $\mathrm{Cu}(1.54 \mathrm{~nm})$ voltage $40.0 \mathrm{kV}$, current, $30.0 \mathrm{~mA}$ Scan range: 10.0000 <$>{ }^{\circ} 90.0000$ Step size: $0.0200^{\circ}$ Time: 0.15 s DS aperture: $1.00^{\circ} \mathrm{SS}: 0.30 \mathrm{~mm}$.

\subsection{Corrosion tests}

Al electrochemical investigation was performed with polarization by potentiostat. All experiments tested with a computer (PCI4 / 750, GAMRY Instruments, Inc., Warminster, PA) in a 3.5 percent $\mathrm{NaCl}$ solution at room temperature. $\mathrm{Ag}$ / $\mathrm{AgCl}$ is used in electrochemical cells as a reference electrode, $(\mathrm{Pt})$ auxiliary electrodes, and working electrode. The solvent was exposed to the surface sample. The area shown was approximately $10 \mathrm{~mm}^{2}$. Before each experiment, samples were given a metallographic polish and then washed by distilled water and acetone. Samples were submerged in solution until constant open circuit potential (OCP) was obtained. Polarization scanning was performed at $\left(1.0 \mathrm{mV}^{\mathrm{s}-1}\right)$. Calculated with Echem Analyst to fit the same experimental results [18].

\section{Results and discussions}

\subsection{Microstructure examination}

Fig (2a) shows pure aluminum optical microstructures prior to addition of nanoparticle phosphates. Initially, metal phosphates nanoparticles consist of large grains with an average grain size of $150 \mu \mathrm{m}$.

Fig (2b) shows the optical microstructures of pure aluminum after addition of iron-nanophosphates includes downy grains with an average 
grain size of $70 \mu \mathrm{m}$. Iron is a common element for impurities in low concentrations of aluminum alloys that can act as a catalyst for grain refining. Moreover, due to the deleterious effects of iron, the deleterious effect of the Nano-iron process can be neutralized by removing the introduction of equations such as Nano- iron phosphate that can alter the phase shape or increase the precipitation of iron-rich particles [2,10,11].

Fig (2c) shows the optical microstructures of pure aluminum composed of downy grains with an average grain size of $83 \mu \mathrm{m}$ after the added magnesium phosphate nanomaterial. The $\alpha$ matrix of liquid precipitates as dendrites as an initial phase, and it is nominally composed of $\mathrm{Al}$, $\mathrm{MgP}$, AlMg and AlP alloy. For each of our experimental materials, the size of dendrites (resolution and content) are similar but SDAS is slightly different. AlPs particles resemble round grains. However, thick granules were observed at the periphery of the alpha-phase dendrites.

Fig (2d) shows the optical micro-structures made of pure aluminum after addition of nanophosphates and zinc. It consists of small beans with an average size of $65 \mu \mathrm{m}$. The microstructure consists of an Al-ZnP alloy cast from $\alpha$-phase and Zn Particles [7,14]. As an initial stage, the $\alpha$ matrix nucleate from the fluid as form of dendrites, and it is nominally composed of $\mathrm{Al}$ and $\mathrm{Zn}$. The small, round grains noticed alpha-phase dendrites in the periphery. The zinc containing is specially formed between the $\alpha$ dendrites, such as the AlZn phases. Research has confirmed that the length of dendrites and downy arm area in commercial pure aluminum grows with increasing content of phosphate minerals. As this alloy belongs to the typical alloy, despite its zinc content, this is because it has a similar microstructure.

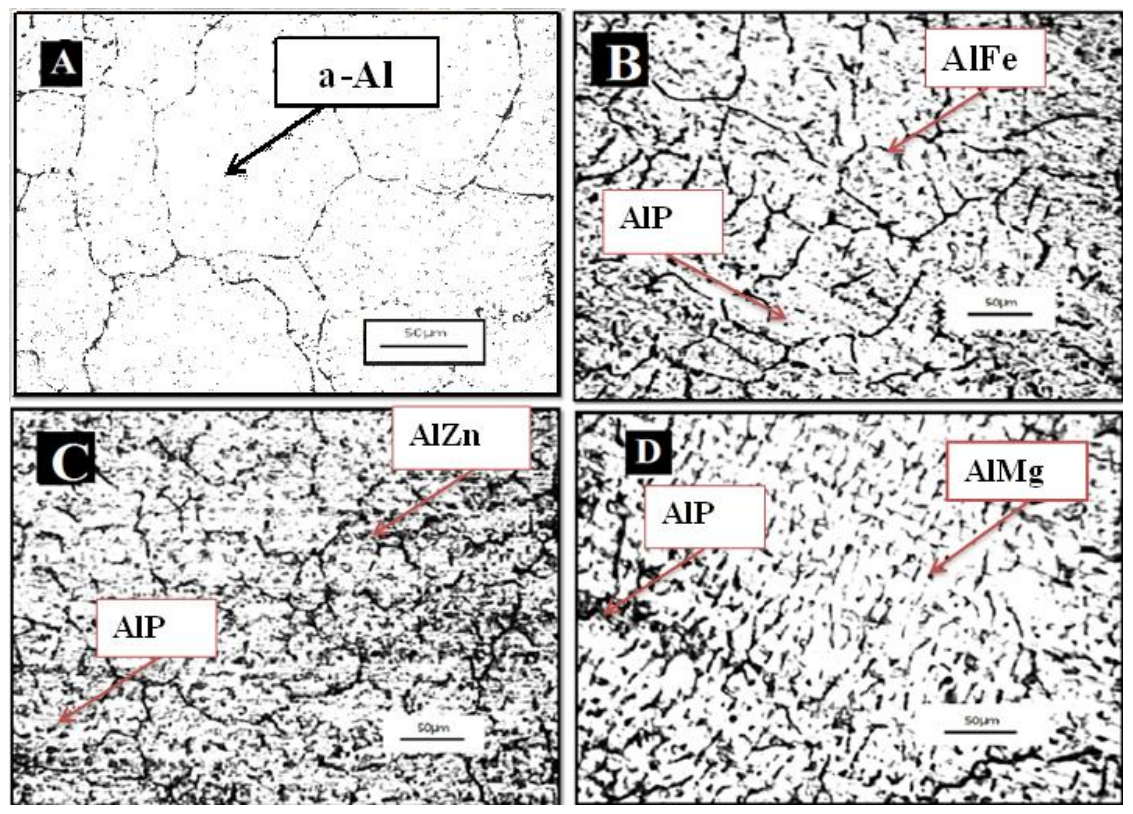

Fig 2. The optical microstructures of pure aluminum before and after additive A-without additive, B- added Nano-iron phosphate, C- added Nano-magnesium phosphate and D-Added Nano-zinc phosphate

The results show mechanical properties increasing with the content of experimental nanoparticle metal phosphate species in Figure (3). The first substance without an additive has a Vickers hardness $(\mathrm{Hv}=77)$. Samples containing nano-iron phosphate have Vickers hardness $\mathrm{Hv}=106.492$, samples containing nano- magnesium phosphate have downy hardness $\mathrm{Hv}=$ 114.271 and samples containing nano-zinc phosphate have Vickers hardness $\mathrm{Hv}=120.492$, the stiffness differences are insignificant, regarding the possibility of Nano-metal phosphate substitution of the change for each $\alpha$ matrix material (downy and content) are very similar. 


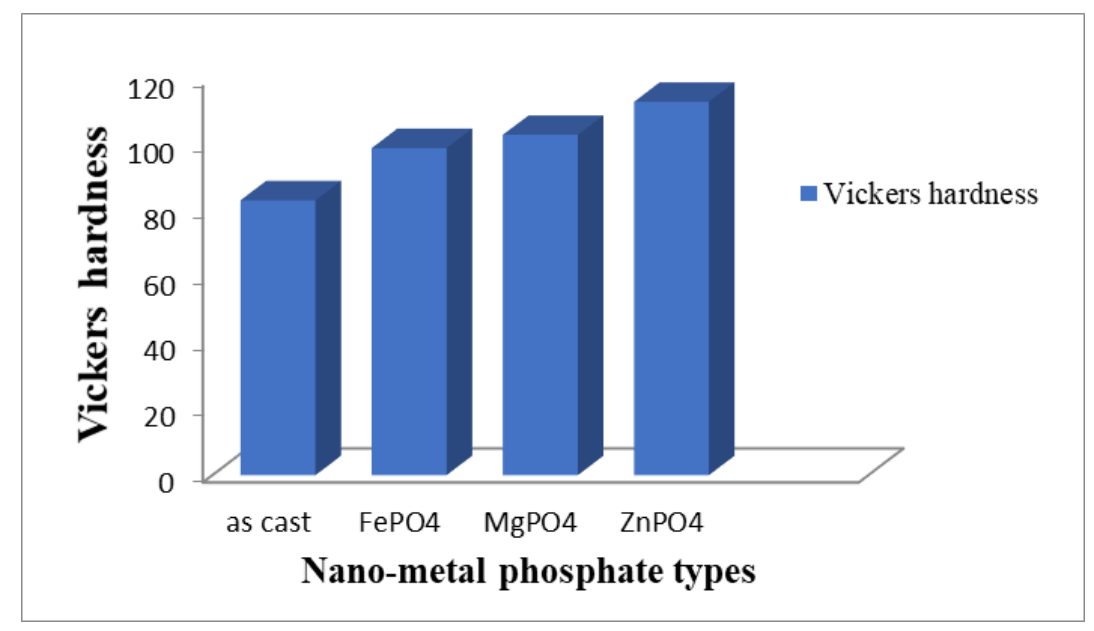

Fig 3. Hardness VS content of Nano-metal phosphate types

\section{$3.2 X$-ray pattern texture}

The X-ray diffraction pattern of aluminum treated with nanoparticle phosphates as shown in Fig. (4) shows (111), (200), (220) and (311) distinct peaks for the Al FCC. The solubility of $\alpha$ Al doping is exceeded during solidify [11]. No peaks were detected for $\mathrm{Mg}_{2} \mathrm{Si}$ although the alloy should be able to precipitate it.

Preferred directions are found during the solidify of the molten metal, since one part of the granule grows faster than the others, that is, the formation of a crystalline texture. Curing technique, solidification, deformation, annealing, and phase shifting control this crystal tissue. Texture type is named accordingly, i.e. there is texture for hardening, texture for deformation, grain growth texture and recrystallization, and transformation texture. A texture is one in which the crystals have a preferred orientation, while when the directions are random, a less textured material is used [15]. Since Al is a FCC metal, columnar grains usually have $\langle 100\rangle$ axes $[11,12]$, that is, the fiber texture at $\langle 100\rangle$. Texture is categorized as large structure and microstructure.

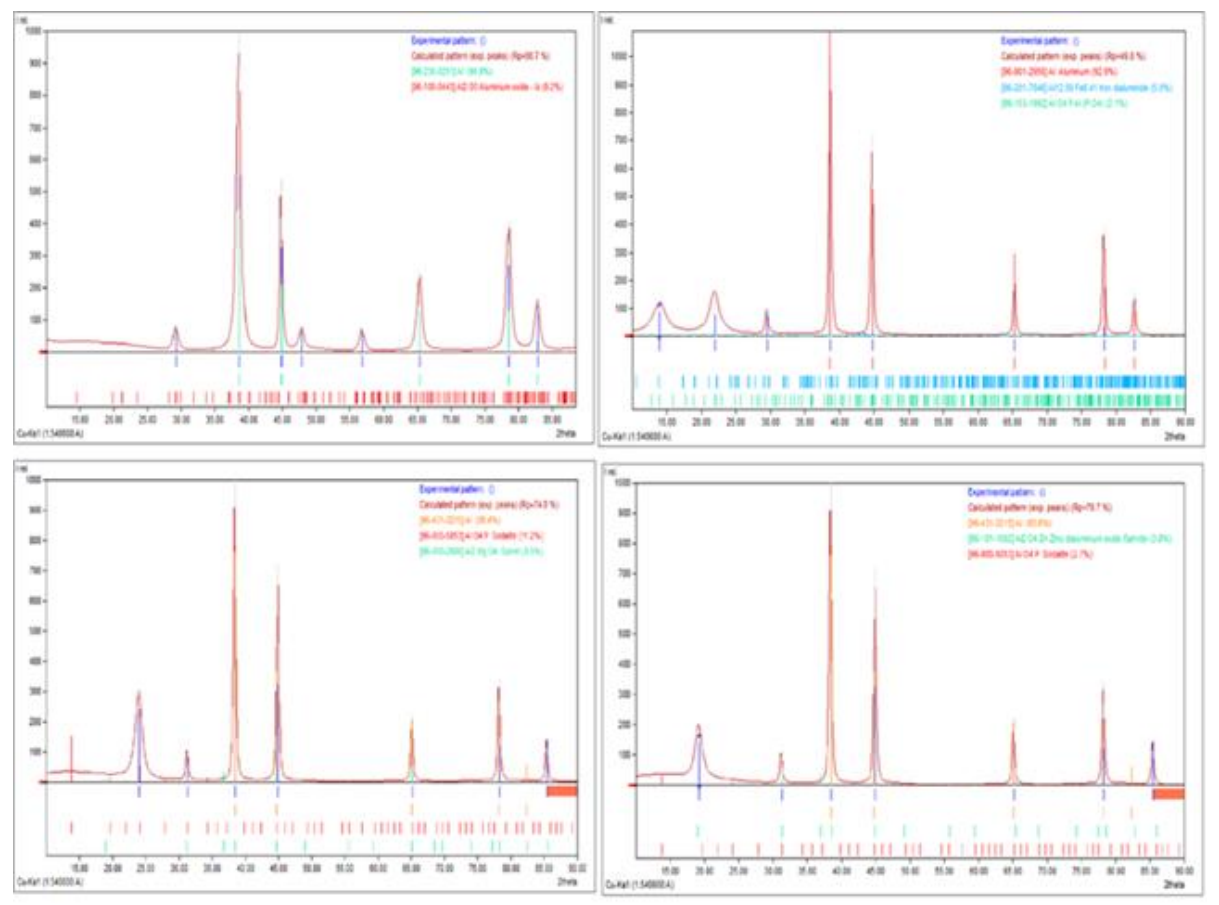

Fig 4. XRD pattern for pure $\mathrm{Al}$ samples with contenting of Nano-metal phosphate types 


\subsection{Corrosion behavior}

Fig.5 show the cyclic polarization curves were determined to surmise the electrochemical stability of the samples tested in 3.5 percent $\mathrm{NaCl}$. The cyclic polarization measurements were carried out in order to assess the polarization domains for analyzed samples. The cyclic polarization curves indicated the three possible domains: the passive field, the cathodic field, and the trans-passive field. For the analyzed sample, the larger passive field and lower value of the current density in the transient field show higher corrosion resistance $[1,4]$. Pitting corrosion is observed preferentially in the alloy. With pure $\mathrm{Al}$, the density and size of the corrosion pits increased.

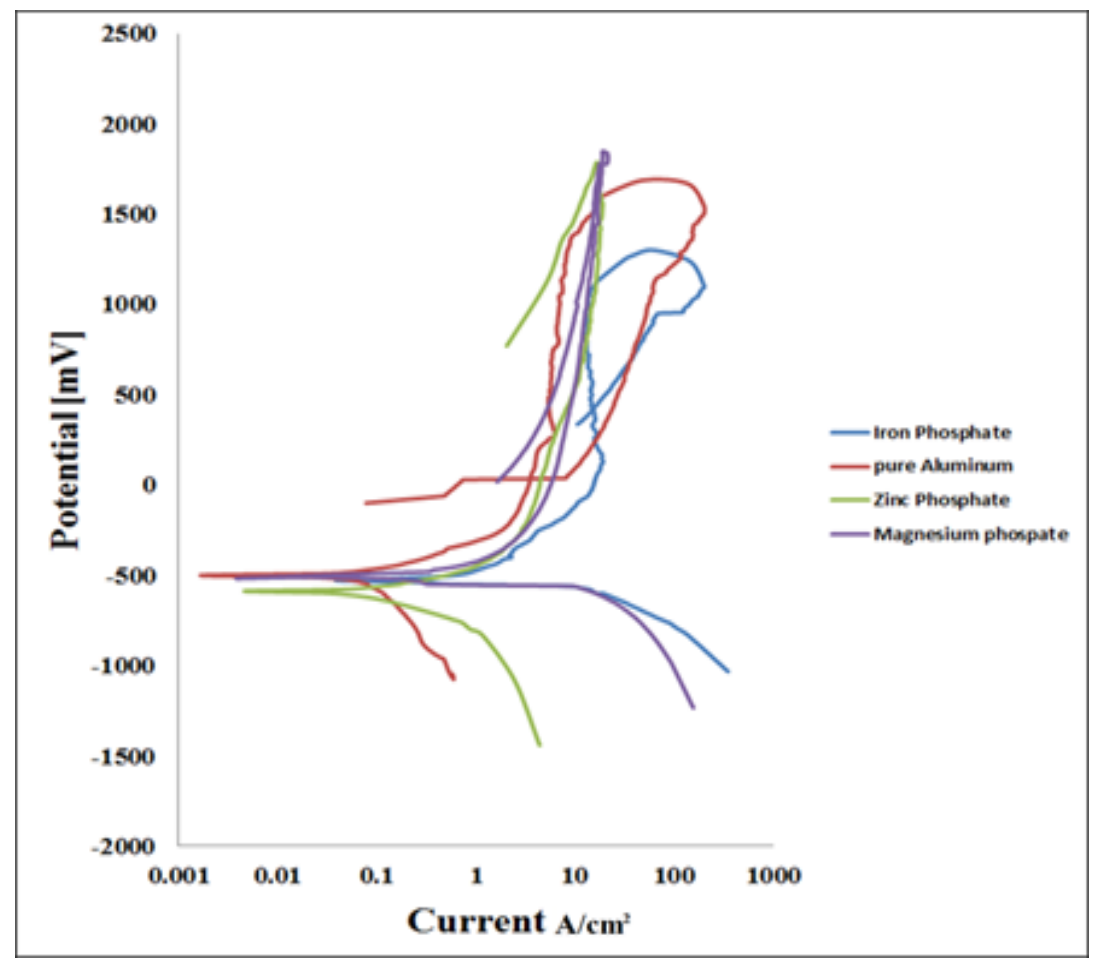

Fig 5. Cyclic polarization curves of the experimental materials in $3.5 \% \mathrm{NaCl}$ solution

Indeed, the Tafel slopes and the related computed uniform corrosion rates for a metal coated with a semiconducting oxide passive film raised strong suspicions although a Tafel extrapolation method was used to determine the corrosion rates of Al-based alloys, and Table 3 shows the results of the electrochemical corrosion at $3.5 \mathrm{~g} / \mathrm{L} \mathrm{NaCl}[6,8,9)$. The polarization curve of pure $\mathrm{Al}$ showed an active degradation near $\mathrm{E}_{\text {corr }}$, followed by an apparent increases of the current with the applied potential due to thinning and weakening of the negative layer as a result of $\mathrm{Cl}$ anions attack as shown in Fig (6a). Moreover, the periodic polarization curves illustrate the behavior of the Tafel in Fig. (5). This was evident in Al's Ecorr strands with added nano- phosphate elements, which showed some types of potential full-scale bending applied. 

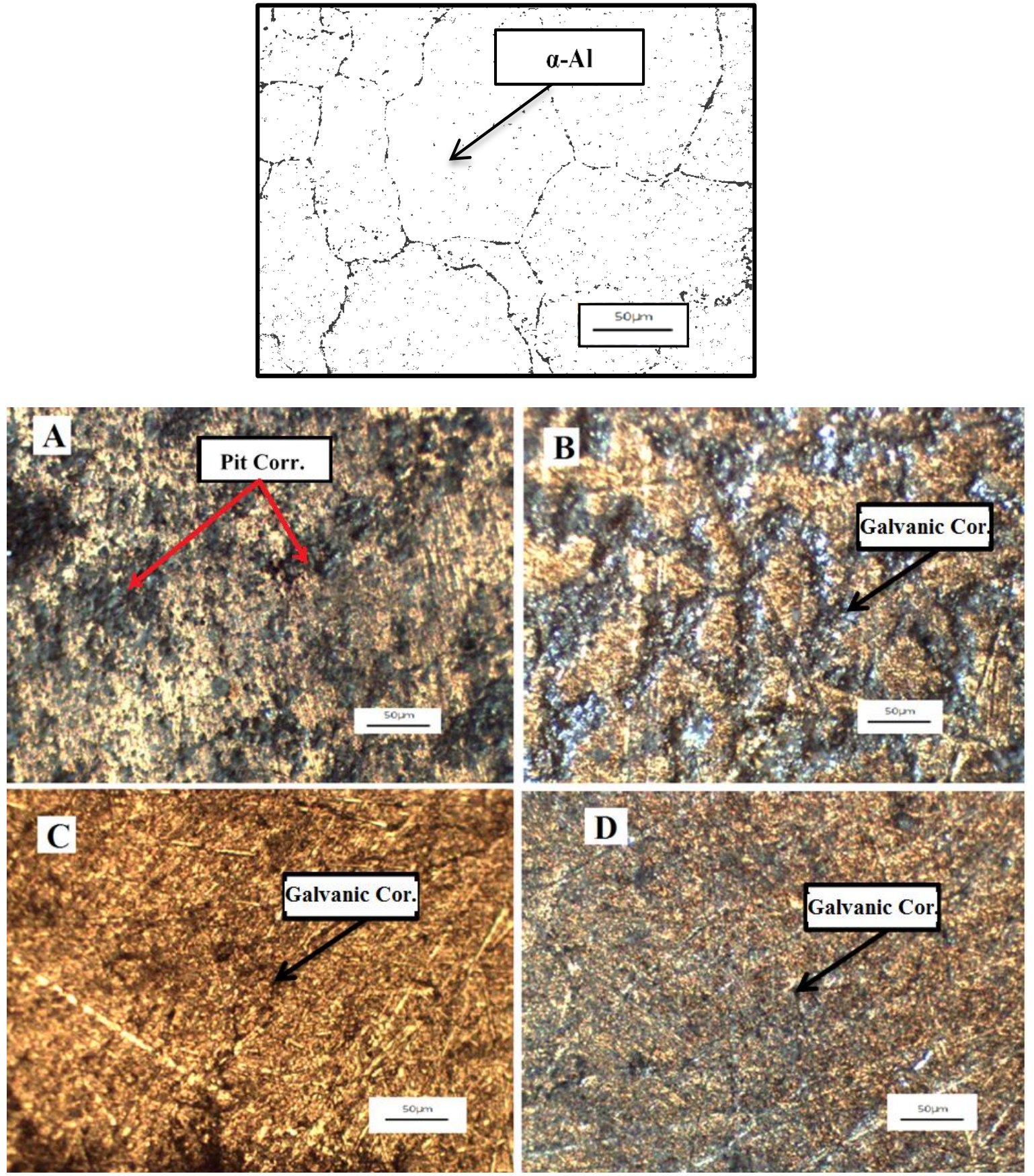

Fig 6. Microstructure characteristics of the tested alloys after corrosion test

Table 3. Results of electrochemical corrosion in $3.5 \mathrm{~g} / \mathrm{L} \mathrm{NaCl}$

\begin{tabular}{|c|c|c|c|c|}
\hline Samples & $\mathbf{E}_{\text {corr }}(\mathbf{m V})$ & $\mathbf{i}_{\text {corr }}\left(\mathbf{m A} / \mathbf{c m}^{2}\right)$ & ba [mV/Dec] & bc [mV/Dec] \\
\hline As received & -516.1 & 16.18 & -118.5 & 152.0 \\
\hline At added Fe(PO$)$ & -502.5 & 14.51 & -305.3 & 157.2 \\
\hline At added $\mathbf{M g}\left(\mathbf{P O}_{4}\right)$ & -492.2 & 12.21 & -148.7 & 149.7 \\
\hline At added $\mathbf{Z n}\left(\mathbf{P O}_{4}\right)$ & -485.9 & 9.03 & -136.3 & 95.4 \\
\hline
\end{tabular}


The effect of $\mathrm{Fe}\left(\mathrm{PO}_{4}\right)$ on pitting corrosion of aluminum alloys as a result of micro-galvanic corrosion processes begins at the interface between the $\alpha$-Al matrix and the iron-rich metal. General, irregular corrosion attacked the samples, and gray corrosion products covered their surface. Microscopic observations confirmed the significant activity of Al- $\mathbf{F e}\left(\mathrm{PO}_{4}\right)$ compared to corrosion with pure $\mathrm{Al}$. The separation at the grain boundaries leads to galvanic inter-grain corrosion effects. Using microscopy, evaluation of the Al- $\mathbf{F e}\left(\mathbf{P O}_{4}\right)$ surfaces after an exposure test showed that sites with localized corrosion pits were present on the surface Fig (6b).

Fig 5(c,d) shows a micrograph that confirmed the negative Al- $\mathbf{Z n}\left(\mathbf{P O}_{4}\right)$ and Al$\mathbf{M g}\left(\mathrm{PO}_{4}\right)$ corrosion in comparison to the pure $\mathrm{Al}$. In addition, the Al- $\mathbf{Z n}\left(\mathbf{P O}_{4}\right)$ and $\mathrm{Al}-\mathbf{M g}\left(\mathbf{P O}_{4}\right)$ alloys tend to be passivated with a low current coverage a long range of potentials. Reflecting these strong negative results and its higher propensity to resist, the anodic polarization curve showed a typical negative layer, indicating its high resistance to corrosion. The negativity of the studied alloys persisted until pitting ability ( $\left.\mathrm{E}_{\mathrm{pit}}\right)$ was reached. Marked changes occurred in potentials beyond $E_{\text {pit }}$ within a very narrow passive region. This participation in the reverse potential scan did not increase the corrosion current density and form the smallest of or without the slowing down loop. These events were a clear sign of resistance to class passivity and the onset and spread of corrosion [ $7,10,14]$.

\section{Conclusions}

The microstructure, corrosion and mechanical properties behavior of cast pure aluminum have been examined, and the following findings are written from this study.

1- Modification of metallic nanophosphate reduced the size of the microstructure particles.

2- The oxide layer index is increased by adding $\mathrm{Zn} \mathrm{PO}_{4}$, and the corrosion resistance is increased.

3- There is a good relationship between the oxide layer (ie the level of melt quality) and the corrosion resistance regardless of the metal nano-phosphate.

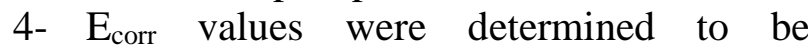
approximately equal for all conditions and samples were stirred slowly.

5- In pure $\mathrm{Al}$, the lowest corrosion rate was obtained by modified zinc $\left(\mathrm{PO}_{4}\right)$.

\section{References}

[1] V. Dumitrascu, L. Benea, and E. Danaila, "Corrosion Behavior of Aluminum Oxide Film Growth by Controlled Anodic Oxidation," IOP Conf. Ser. Mater. Sci. Eng., vol. 209, no. 1, 2017.

[2] M. E.-S. M. EL-Bedawy, "Effect of Aging on the Corrosion of Aluminum Alloy 6061," 2010 pp. 189 ,

[3] H. De Oliveira, F. Morais, C. Terui, P. O. Box, and S. Paulo, "Corrosion Performance of Al-Si-Cu Hypereutectic Alloys," vol. 8, no. 2, 2005, pp. 155159 ,

[4] F. J. Hernández, J. J. Santana, R. M. Souto, S. González, and J. Morales, "Characterization of the atmospheric corrosion of aluminum in archipelagic subtropical environments," Int. J. Electrochem. Sci., vol. 6, no. 12, 2011, pp. 6567-6580.

[5] A. A. Mazhar, S. T. Arab, and E. A. Noor, "The role of chloride ions and $\mathrm{pH}$ in the corrosion and pitting of Al-Si alloys," J. Appl. Electrochem., vol. 31, no. 10, 2001, pp. 1131-1140.

[6] B. Grgur and L. Marunkić, "The influence of chloride anions on the pitting corrosion of aluminum alloy en 46000," Zast. Mater., vol. 59, no. 2, 2018, pp. 243-248.

[7] L. Zhang, S. Hong, J. He, F. Gan, and Y. S. Ho, "Isotherm study of phosphorus uptake from aqueous solution using Aluminum Oxide," Clean Soil, Air, Water, vol. 38, no. 9, 2010, pp. 831-836.

[8] M. Abdulwahab, A. Kasim, S. A. Yaro, O. S. I. Fayomi, and O. B. Umaru, "Effect of Avogadro Oil as Corrosion Inhibitor of Thermally Pre-aged AlSi-Mg Alloy in Sodium Chloride Solution," Silicon, vol. 5, no. 3, 2013, pp. 225-228.

[9] G. Access, "Don' t miss out on relevant research Don' t miss out on relevant research," Elsevier, vol. 15, pp. 1-2, 2019.

[10] H. W. Doty, "Beta Al 5 FeSi phase plateletsporosity formation relationship in A319. 2 type alloys," 2020, pp. 1-8. 
[11] U. D. O. D. Rangel et al., "Corrosion and Microabrasive Wear Behaviour of 2524-T3 Aluminium Alloy with PAni-NPs/PSS LbL Coating," Mater. Res., vol. 22, no. 3, 2019.

[12] M. Al Nur and M. S. Kaiser, "Corrosion Behaviour of Hypereutectic Al-Si Automotive Alloy in Different pH Environment," Int. J. Mech. Mater. Eng., vol. 11, no. 11, 2017, pp. 1771-1775.

[13] L. Kuchariková, T. Liptáková, E. Tillová, D. Kajánek, and E. Schmidová, "Role of chemical composition in corrosion of aluminum alloys," Metals (Basel)., vol. 8, no. 8, 2018, pp. 1-13.

[14] E. S. M. Sherif, J. A. Mohammed, H. S. Abdo, and A. A. Almajid, "Corrosion behavior in highly concentrated sodium chloride solutions of nanocrystalline aluminum processed by high energy ball mill,’ Int. J. Electrochem. Sci., vol. 11, no. 2, 2016, pp. 1355-1369.
[15] E. R. Elsharkawy, “Corrosion Behaviorof Aluminum Alloy 6061withgrain RefinerAl- 6Tiin Salt Solution $(3.5 \% \mathrm{NaCl})$ After Heat Treatment," Int. J. Eng. Sci., vol. 06, no. 01, 2017, pp. 05-11.

[16] N. Nnaji, N. Nwaji, J. Mack, and T. Nyokong, "Corrosion resistance of aluminum against acid activation: Impact of benzothiazole-substituted gallium phthalocyanine," Molecules, vol. 24, no. 1, 2019.

[17] J. A. Moreto et al., "On the global and localised corrosion behaviour of the AA2524-T3 aluminum alloy used as aircraft fuselage skin," Mater. Res., vol. 22, no. 2, 2019.

[18] M. T. Mohammed, H. A. Hussein, I. N. Jasim, and Z. I. Allawi, "Effect of compaction pressure on morphology and physical properties for $\mathrm{Cu}$-based produce by using powder metallurgy technique," 1st Int. Sci. Conf. Eng. Sci. - 3rd Sci. Conf. Eng. Sci. ISCES 2018 - Proc., vol. 2018-Janua, 2018, pp. 198-202. 